\title{
La teología en tiempo de SIDA
}

\author{
Enda MacDonagh, \\ Maynooth College, \\ Irlanda.
}

\section{Introducción: teología, narración y signos de los tiempos}

La teología vive siempre en el tiempo, y de ahí le viene la necesidad de ser también, en parte, narrativa. Fuera del tiempo, antes y más allá de él, ni se necesita teología, ni es posible la narración. Esta pequeña reflexión, obvia por otra parte, lleva a preguntamos por la realidad del tiempo, que sigue siendo tan misterioso para nosotrd's como lo era para san Agustín. Cronos y kairos, las dos palabras griegas clave para designar el tiempo, siguen siendo útiles para distinguir el tiempo objetivo y mensurable, lo que ahora se llama tiempo de reloj, y el tiempo que es subjetivamente significativo para la persona y la comunidad. Este último es el kairos, el tiempo histórico, que, para judíos y cristianos, indica el momento y el acontecimiento de la llamada divina, a la cual el ser humano debe responder. Kairos fue el anuncio del reino de Dios que hicieron los profetas y Jesús. Y fue kairos por ser momento de la especial presencia y comparecencia de Dios entre los seres humanos.

Cronos y kairos se distinguen, pero no se pueden separar, lo cual la teología, dado su carácler marcadamente temporal, debe de tener en cuenta. El cambio en teología, como en todo to humano, se relaciona con el tic-lac del reloj, con la dimensión biológica del ser humano. Y el significado de ese cambio se relaciona con el ser humano como sujeto y con su capacidad para leer los signos de los tiempos. Según esto, hablar de "teología en tiempo de SIDA" significa tomar en serio el período-liempo (cronológico) desde la primera diagnosis (reciente) del SIDA, en 1981, hasta los años 2000 , más su posterior desarrollo hasta convertirse en pandemia mundial. Pero signfica mucho más que eso, pues ese período de liempo se coniverte en kairos para la teología.

Hablar de "teología en tiempo de SIDA" recoge algo del tono melodramático del título de la novela de García Márquez, Amor en tiempos de cólera, aunque 
en los últimos viente años la historia del SIDA es más trágica que melodramálica. Dicho esto, debemos preguntamos por qué buscar un significado teológico en la realidad del SIDA, y no, por ejemplo, en el cólera o en la tuberculosis, tan extendida ésta, de nuevo, y en formas novedosas más resistentes. Y debemos preguntamos también por qué buscar en absoluto un significado teológico para una época caraclerizada por grandes enfermedades u otras crisis ¿Es que tuvimos una teología para la "muerte negra" o para alguna de las grandes guerras?

La pregunta no es ociosa. Aunque quizás no con esas palabras, los profetas de Israel, el mismo Jesús y los grandes pensadores religiosos y los teólogos, desde san Agustín a Barth, siempre han buscado respuestas a las crisis de su tiempo, y lo han hecho como si éstas fueran llamadas de Dios, concretas, ineludibles. Llamar crisis a la realidad de una época, y relacionarla con la teologia, quizás no pase de ser una moda reciente, como cuando hablamos de una "teología para la era nuclear". Pero, más allá de las formulaciones, existe una larga y poderosa tradición de ofrecer orientación teológica y proponer reflexiones religiosas ante las crisis humanas, que van surgiendo a lo largo de la historia.

Volvamos al SIDA. Según las últimas estadísticas, la infección producida por el virus de inmunodeficiencia humana (VIH), causante del SIDA, está mucho más extendida de lo que se pensaba hasta ahora. ONUSIDA estima que al final del año 2001 había en el mundo $\mathbf{4 0}$ millones de personas con VIH (de las cuales el $\mathbf{4 8}$ por ciento son mujeres). En muchos países en vías de desarrollo, la mayoría de las nuevas infecciones se producen en adultos jóvenes, siendo particularmente vulnerables las mujeres jóvenes. Se considera que, desde que comenzó la epidemia, más de 60 millones de personas han quedado infectadas por el VIH. De las personas que actualmente están infectadas, cerca de una tercera parte liene entre 15 y 24 años de edad. De éstas, la mayor parte no sabe que son portadoras del virus, y muchos otros millones de personas no saben nada $\longrightarrow$ muy poco- acerca del VIH para poder protegerse contra él.

También es importante recalcar el cambio que ha habido en el conocimiento del modo de propagación del SIDA. Al principio se pensaba que ésta era una enfermedad de homosexuales y drogadiclos - por culpa propia, según algunos analistas-, pero se ha ido constatando que, en la actualidad, la relación heterosexual es el medio más común de transmisión, y que ningún grupo, de cualquier clase o raza, género u orientación sexual, está inmune a la infección del VIH.

Lo dicho muestra que estamos "en tiempo de sida" (en la línea del cronos), pero es evidente que su significado no puede ser expresado sólo en números fríos. Para captar su significado actual (en la línea del kairos), se necesita conocer las historias de individuos, de familias y sociedades enteras, devastadas por el miedo, el sufrimiento y las muertes, que han ocurrido en todo el mundo, durante las últimas décadas. Por ello, para captar el desafío que supone hacer "teología en tiempo de SIDA" es necesario escuchar esas historias y dejarse impactar por 
quienes las cuentan, personas que también viven con el VIH-SIDA, ellas, sus familias, sus compañeros, sus amantes, las personas que las atienden. Y para los teólogos que desean comprometerse en la lucha contra el SIDA, sería todavía mucho más iluminador la práctica de cuidar a los afectados y sufrir con ellos. A partir de tales historias y prácticas, de sufrimiento y de compasión, se podrá hacer una nueva reflexión teológica.

Estas historias son la base de la reflexión teológica que está haciendo la Confederación Intemacional de Servicios Nacionales Católico-sociales, organizada por Carilas Internationalis, y las organizaciones de desarrollo, que han cooperado con iniciativas locales, en todo el mundo para dar una respuesta, católica y cristiana, a los desafios del VHH y del SIDA. En contextos tan diferentes como Norteamérica y el Sureste de Asia, el Caribe, Europa y Africa, este grupo ha estado, a la vez, enseñando y aprendiendo, escuchando, crilicando y volviendo a contar las historias, los análisis y las prácticas, que él mismo ha experimentado.

Las reflexiones que presentamos a continuación quisieran ser un intento mediador entre estas experiencias y la tradición teológica católica, aunque, desgraciadamente, no podemos presentar ahora en detalle dichas experiencias.

\section{La reflexión teológica: algunas reflexiones previas}

Cualquier crisis murdial, las historias angustiosas y heroicas de sufrimiento humano, siempre necesita una respuesta, una reflexión cristiana y algún tipo de teoría teológica. Siendo esto verdad, hay que tener presente desde el principio que, más allá de su alcance mundial y de la cruel brusquedad con la cual ha emergido, la crisis del VIH-SIDA tiene características especílicas, pues aúna, en devastadora mezcla, dos poderosas realidades del ser humano: el sexo y la muerte. El modo en que esta mezcla afecta a la teología, y en particular a la teología moral, será el primer punto a tratar.

\subsection{Volver a contar, a reflexionar y a leer las fuentes}

La historia, todavía corta, pero poderosa, de la pandemia del VIH/SIDA y la breve historia de los grupos y las actividades de Caritas Internationalis llevan a la narración y exigen una reflexión para releer y volver a contar las tradiciones cristianas, que sostienen e inspiran al grupo. Este volver a contar y reflexionar Ileva a una relectura de las escrituras y tradiciones cristianas, que puede ayudar, por una parte, a comprender las omisiones e incomprensiones en el modo de tratar el problema del VIH-SIDA, y, por otra, a abrir camino, al menos, a una comprensión más auténtica y plena.

Un ejemplo. Las teologías de la liberación de los latinoamericanos, de los negros y de las feministas, son sólo los ejemplos más recientes de la seriedad con que los desafíos sociales — con nuevas pregunlas sobre el significado buma- 
no y sobre la moralidad que está detrás de esas realidades - han obligado a una nueva relectura, seria y fructífera, de esas escrituras y tradiciones. Por una parte, sería temerario pretender que el VIH/SIDA pueda llegar a tener implicaciones de tan largo alcance para la práctica de la teología y la comprensión de la fe cristiana. Pero, por otra, la experiencia de liberación, que está en la base de muchas teologías, debería alertamos a no infravalorar el impacto que puede tener la pandemia del VIH-SIDA, en el pensamiento y en la práctica cristiana. En cualquier caso, debería impedir que el debate sobre el VIH-SIDA se reduzca a cuestiones marginales, aunque tengan su importancia, como el uso de preservativos o el intercambio de agujas, en los programas de prevención.

Y no sólo eso. Las cuestiones que plantea el VIH-SIDA a la teología no se reducen a la leología moral. Sus desafíos van más allá de ella. La nueva lectura teológica de las fuentes, con ocasión del VIH-SIDA, debe examinar seriamente cuestiones esenciales para la fe cristiana y para una vida en base a ella. Veámoslo en momentos importantes de la revelación.

\subsection{La presencia de Dios y el poder divino}

La teología trata, ante todo, de Dios. Por ello, el debate teológico "en tiempo de SIDA" tiene que empezar con Dios. Lesley Houlden sostiene que, estrictamente hablando, la pandemia VIH-SIDA no lleva a nuevas preguntas sobre Dios, ni, en general, presenta ningún problema teológíco nuevo. La idea no es absurda, pero tampoco se puede negar que la pandemia plantea al menos algunas "antiguas" preguntas, aunque, ahora, en formas "nuevas" y graves para las personas afectadas.

Posiblemente es el libro de Job el que expresa la reflexión más profunda sobre la relación entre el sufrimiento humano y el poder y la presencia de Dios, en el mundo. Pues bien, los sufrimientos físicos de Job, su angustia psicológica ante el futuro y su ira, ciertamente, pueden hallar comprensión en lectores contemporáneos que hoy luchan con el VIH-SIDA. Esto no quita que nuevas generaciones experimenten aspectos esenciales del problema de Job de maneras muy distintas, pues viven su sufrimiento en un marco de creencias, dudas religiosas y personales y ambientes culturales -incluso expeclativas médicas - muy distintos al de Job.

Pero puede haber analogías. Al enfrentarse con el "Dios misterioso de la tempestad", el que pone, creativamente, los cimientos de la tierra, y la diferencia de la vida animal, Job queda atemorizado y humilde ante la presencia y el poder de su creador, vengador y salvador. De esta forma, Job gana su primer debate a sus "amigos": el pecado personal no es la causa del sufrimiento, él no está siendo castigado por Dios por causa de sus pecados. Esta primera conclusión hay que repetirla también hoy, pues el surgimiento y la proliferación del VIHSIDA pudiera confirmar esa visión de Dios. A los cristianos que todavía creen 
que el sufrimiento humano es un castigo de Dios por los pecados personales, hay que leerles constantemente el libro de Job.

Recordar, sin embargo, la presencia del poder de Dios "en medio de la tempestad", su misterio y su majestuosidad, no resuelve lodas las dificuliades, aunque sí muestra que, en definitiva, los caminos de Dios, por lo que toca a la creación y la providencia, son misteriosos, y toman un giro radical en Jesucristo. El poder y la presencia de Dios, cuyo tiempo (kairos) ha llegado con el anuncio del reino de Dios que hace Jesús, dan una respuesta al sufrimiento humano muy diferente de la que ofrece la proclamación del poder, que se manifiesla "en la tempestad". Dejando de lado ahora el propio ministerio de Jesús con los enfermos - a lo cual volveremos-, nos encontramos, ante todo, con que el misterio de Dios penetra toda la condición humana, hasta el punto que él acepta el sufrimiento humano y acepta morir, en la pasión y muerte de Jesucristo.

La revelación crucial -y cruciforme- del co-sufrimiento (compasión) de Dios con los seres humanos en Jesús manifiesta el nuevo aspecto de ese misterio que llamamos amor. No es fácil comprenderlo, pero a nosotros, seres humanos, nos convence de la presencia de Dios en él. “ ¿Dónde estás tú, Señor, cuando sucumbo ante el dolor y la desesperación?". "Aquí, contigo, junto a ti, como estuve en el Calvario". ¿Y qué ocurre, entonces, con el poder, la omnipotencia de Dios, como soliamos decir? Dios no está ahora más ausente o frustrado que en el Calvario, sino que, a través de la fragilidad de las criaturas y del cuerpo, muestra su "poder", de una manera misteriosa, moviendo a cicatrizar el sufrimiento, en el amor y en la vida, lo cual puede manifestarse $\longrightarrow$ no- en la recuperación de la vida del cuerpo y la salud. El amor infinito que resistió el Calvario no abandona a aquellos por quienes —en el inicio- sufrió el Calvario.

\section{Jesús y el reino}

No hay que reducir a Jesús y a su Dios a la pasión y muerte en el Calvario. Ambas expresan, sin lugar a dudas, el clímax de su vida y su misión, tal como aparece en el evangelio. Sin embargo, esto sólo puede comprenderse plenamente y con propiedad a partir de la vida pública de Jesús y de su ministerio, prosiguiendo su misión y afrontando su destino. Con el anuncio del reino de Dios, Jesús inauguró el ministerio y, al mismo tiempo, confirmó y transformó la tradición de Israel. El tema del reino en Israel sugería la restauración de un reino como el de David, con el Dios de Israel, Yahvé, de nuevo presente con todo su poder y gloria. La presencia poderosa que ofrecía Jesús, en el nombre de su Padre, no era menos gloriosa para aquellos que tuvieran ojos para ver, pero era tan paradójica que no fue comprendida por muchos de sus contemporáneos, quienes quedaron defraudados.

No era un reino para los ricos y poderosos, quienes, por el contrario, tenían que deshacerse de lodas sus riquezas. Los pecadores y las prostilutas, en cam- 
bio, los pobres y los marginados sociales, los leprosos y los recaudadores de impuestos, ésos serían los primeros en entrar en el reino. Identificándose con ellos, comiendo y bebiendo con ellos, Jesús destruyó los cánones establecidos de respetabilidad religiosa y política. Esto es lo que lo llevó a un juicio amañado, y por lo que fue crucificado entre dos criminales, fuera de las puertas de la ciudad. Al declararlo criminal y al ejecutarlo, alcanzó su clímax la exclusión de aquel que había hecho de los excluidos el centro de su misión. La importancia para hoy es clara. Para aquellos cristianos que sientan el impulso a rechazar o evitar o ignorar a las personas que viven con el VIH-SIDA, el ejemplo de Jesús debe ser un recordatorio permanente.

Jesús no sólo buscaba la compañía de los excluidos, sino que pensaba que, actuando así, establecía un nuevo tipo de relaciones entre los seres humanos, un nuevo tipo de comunidad, un nuevo Israel, que haría vigente el reino de Dios que él anunciaba. En esta nueva comunidad, la presencia y el poder de Dios son evidentes, sobre todo en el amor, y en el verdadero amor: dar de comer a los hambrientos, liberar a los presos, dar vista a los ciegos, hacer caminar a los lisiados, curar todo tipo de enfermedades.

Esta dedicación de Jesús a los pobres ha inspirado a muchas generaciones de cristianos. Jesús rechazó totalmente el consuelo —erróneo- que le ofrecían a Job, tratando de explicar la razón de su sufrimiento. "Ni este hombre ni sus padres han pecado", decía Jesús a sus discípulos a propósito de un hombre que había nacido ciego. Con la curación del ciego expresaba, más bien, el poder y la gloria de Dios, quien se preocupa de las necesidades más inmediatas de los que sufren y de los excluidos.

También el nuevo Israel sería para Jesús una nueva creación, consinuida con los poderes que Dios nos dio en la creación, restablecidos ahora y reconfigurados. En la dedicación cristiana a los que sufren y en el progreso científico humano, estos recursos que Dios nos dio se tienen que usar para restablecer la salud y ofrecer consuelo a los afligidos. Amor como el de Jesús, aceptación incondicional y asistencia a los necesitados, tienen que expresarse de todas las formas eficaces posibles, desde un punto de visla médico, social y personal.

\subsection{La teología moral y la ley natural}

La comunidad de discípulos que sigue a Jesús y quiere anunciar y proclamar el reino de Dios para sanar y transformar el mundo debe acluar, a imilación suya, compartiendo su corazón y sus ideas. La comprensión de esas ideas, y su aplicación, en un determinado momento, a los necesitados y excluidos, forman parte de la tarea teológica permanente, que es la ética cristiana. Es ésta una tarea que se debe afrontar usando los recursos que nos aportan los grandes espíritus iluminados por Dios, como san Agustín. santo Tomás de Aquino, Barth y todos los otros grandes pensadores cristianos. 
A través de los siglos, pensadores cristianos, judíos y paganos, han contribuido con vigor a esclarecer la manera en que los cristianos pueden actuar, individual y socialmente, imitando a Cristo. Los intentos más sistemáticos han producido diferentes teologías, aunque relacionadas unas con otras, $y$, en un período tardio de la tradición católica (circa 1600), llegaron a cuajar en lo que se ha llamado teología moral. Nunca ha èxistido una distinción completamente satisfactoria entre la teología moral y las otras ramas de la teología, en especial cuando se endurecían las posturas de los teólogos. En cualquier caso, la distinción era desconocida para Agustín y Tomás.

En las reflexiones que, desde la teología moral, vamos a hacer a continuación, nos centraremos en algunos elementos sistemálicos de un estilo de vida cristiana, según el espíritu de Cristo. Aunque no perdamos el contacto con la Biblia, ni con los desarrollos doctrinales posteriores, es ésta una opción metodológica fundamental. Lo es, ante todo, porque la teología moral católica ha estado dominada, a lo largo de los siglos, por el concepto de la ley natural. Y no es que ésta no lenga su importancia. Con ciertos fundamentos biblicos y, sobre todo, en base a la tradición filosófica occidental, se ha comprobado que la ley natural es de gran valor, tanto para el desarrollo del pensamiento sistemático de la moral cristiana, como en casos particulares. En las misiones de Caritos Internationalis, en varias zonas de Asia y Africa, de limitada base cristiana, la ley natural ha proporcionado un primer acercamiento - aunque sólo sea el primero- para buscar un acuerdo en la comprensión moral del VIH-SIDA entre gentes de diferente procedencia cultural y religiosa. Para los católicos y para quienes comparten un pensamiento filosófico similar, seguirá sosteniendo e iluminando el análisis moral.

Dicho esto, sin embargo, hay que tener en cuenta que lo que la Iglesia o la tradición teológica sostiene sobre la ley natural podría parecer arbitrario $\longrightarrow$ puro autoritarismo, sin verdadera base en la razón a la cual aspira- ante la ausencia de lo que Alastair MacIntyre llamaría "consenso moral público". Además, la corriente crítica de la ilustración hizo difícil defender los argumentos de la ley natural más allá de un limitado círculo religioso. Por ello, el enfoque que adoptaremos en nuestro análisis no se basa directamente en los argumentos de la ley natural. Las fuentes son más bíblicas y teológicas, aunque, sin duda, existirán coincidencias y estarán nutridas de contenidos de la tradición de la ley natural.

\section{Los valores del reino y les virtudes morales}

La nueva presencia y poder de Dios, que se hizo realidad en la vida, ministerio, muerte y resurrección de Jesucrislo, es otra descripción del reino de Dios, que él declaró cumplido en su tiempo (kairos), en base a las promesas que había recibido el pueblo de Israel y en base a las expectativas que Jesús había fomentado -cumplimiento paradójico y desconcertante, como hemos visto. Jesús hizo 
descripciones más amplias y completas del reino en su enseñanza y su ministerio, así como con su muerte y resurrección, a lo cual hay que añadir la respuesta inmediata de sus discípulos. Sin embargo, una lectura somera y fiel de las parábolas de Jesús sobre el reino revela ya lo oscuro y misterioso que éste sigue siendo. Por ello, al hablar de la presencia y del poder de Dios en la historia, que crea y sostiene, que capacita y cura, que ayuda y transforma a la humanidad y al cosmos, es inevitable buscar nuevas descripciones, aunque siempre pobres, del misterio en el cual vivimos y que vive en nosotros.

El reino de Dios que está entre nosotros y con nosotros, según las propias palabras de Jesús, busca y facilita que lo reconozcamos, lo expresemos, lo manifestemos, y que participemos en su desarrollo. En el Génesis se nos llama a participar aclivamente en la actividad creadora de Dios. Jesús también nos llama a participar en la nueva actividad creadora de Dios. ¿Pero quiénes somos "nosotros", los llamados?

"Nosotros" tenemos que estar a la altura de la creación y de la nueva creación. "Nosotros" somos lo primero y lo último de toda la humanidad. Sólo la comunidad de discípulos de Jesús puede reconocer explícitamente el reino. Pero el reino es para todos los seres humanos, y, sobre todo, según el ejemplo y las enseñanzas de Jesús, para los más insignificanles de todos nuestros hermanos, sabiendo que "insignificante", en nuestro mundo deshutnanizado, quiere decir: los pobres, los marginados sociales y los enfermos, que en tiempos y lugares de SIDA pueden fácilmente coincidir. Así, los discípulos de Jesús, con confianza en el reino y capacitados por la llamada del reino, han de ofrecer un camino en respuesta a estos "insignificantes", preocupándose activamente, favoreciendo relaciones afectivas personales y promoviendo reformas esiructurales.

La esperanza que generó la visión del reino que tenía Jesús —proclamada especialmente por los profetas de Israel- es la base para una estructuración moral de la llamada del reino, según ésla afecla a las vidas de los discípulos cristianos y a los objetivos morales de toda la comunidad humana. Este enfoque es sobre todo biblico y teológico. No es el único, pero puede ser muy iluminador, si relacionamos - desde la moral- el reino de Dios y la sociedad humana, en este liempo del VIH-SIDA. En cualquier caso, es el enfoque que vamos a utilizar.

En otra parte he desarrollado más ampliamente el tema de los valores del reino, y por eso aquí los trataré de manera breve. Digamos, de forma programática, que en la tradición bíblica y teológica es posible diferenciar una serie de valores, que se han de realizar en presencia de Dios y del poder de Dios. Algunos de ellos expresan la presencia y el poder del mismo Dios, en las historias de Israel y las de Jesús. Estos valores reflejan la alianza de Dios con su pueblo, así como las relaciones de unos seres humanos con otros, y también las de éslos con Dios. Expresan la auténtica presencia y poder de Dios, en acciones interpersonales y en estructuras sociales. En esta dialéctica de persona y socie- 
dad, los valores del reino preanuncian la realización de la persona y la sociedad, lo cual es, a su vez, un incentivo para las sucesivas alianzas de Dios. La realización de estos valores, aunque sólo sea parcialmente, es la realización del reino con sus limitaciones históricas. Y también —en el transfondo de visiones filosóficas distintas - podrían proporcionar una base para una visión de la sociedad diferente de la judía y la cristiana.

Los cuatro valores del reino que parecen cumplir esta finalidad son los de la verdad, la libertad, la justicia y la paz (shalom). También se les pueden llamar valores primarios del reino, pues reflejan la realidad primaria de Dios. A otros valores, que no son reflejo inmediato de Dios, se les puede llamar valores secundarios. Ello no significa que éstos últimos no sean importantes, sino que no son por sí mismos atributos de Dios. Los atribulos lípicos de nuestra condición carnal, como por ejemplo la castidad, no se pueden aplicar a Dios y, en este sentido, son secundarios.

\subsection{La presencia y el poder de Dios en la vendad}

El objeto sobre el que versa la pregunta de Pilatos "qué es la verdad", en loda su complejidad hermenéutica, debe ser abordado en otro momento y en otro lugar. Por lo que toca a nuestro propósito, baste decir que la verdad es fundamental en las tradiciones judía y cristiana, tan fundamental como Dios. Es Dios. Más exaclamente, Dios es la verdad. La realidad definitiva que se revela a sí misma es una verdad esencial para la humanidad, que al mismo liempo convoca y capacita a los seres humanos para reconocer la verdad y vivir en ella. Sólo escuchando la llamada de Dios a la verdad, buscando o, al menos, consiguiendo una parte de la verdad, luchando por ello y viviendo en ella, los seres humanos pueden vivir unos con otros. Así, la dialéctica persona y sociedad exige una mínima sinceridad, para poder solucionarla de modo satisfactoria $-\mathrm{y}$ tales "mínimos" son expresiones del reino, de la presencia y del poder de Dios.

En la hisloria, crisis sociales y personales, como la guerra y la pandemia del VIH-SIDA, amenazan la verdad. Esto quiere decir que, al menos sin un compromiso continuo con la verdad, la crisis no se comprenderá de forma adecuada y la respuesta será equivocada. La tentación, por ejemplo, de ocultar la verdad sobre la verdadera magnitud de la pandemia es sólo un aspecto de cómo esa amenaza puede agravar la crisis. Un temor al contagio de la familia, de los amigos, de los que ayudan, basado en falsedades, puede con facilidad minar las respuestas sociales o personales adecuadas. Sólo la verdad, según la frase del evangelio, nos hará libres para combatir realmente la crisis. Y es esa hambre de verdad, divinamente concebida, la que, a través de la investigación, puede ir descubriendo formas médicas de prevención y curación.

A veces, el valor de la verdad puede entrar en algún tipo de conflicto con otros valores. Los problemas de confidencialidad e información, que se presen- 
tan a las personas que viven con el VIH-SIDA, así como a sus compañeros y asistentes, son bastante complejos, tanto desde un punto de vista médico como social. Puede que no sea siempre fácil respetar la verdad, en un contexto en el cual es difícil distinguir los derechos personales a la vida privada y la dignidad, por una parte, y la exigencia social a la salud pública, por la otra. En esa situación, otros valores del reino, como la libertad, la justicia y la paz-solidaridad desempeñarán un papel relevante para encontrar la solucion adecuada -como ocure en la mayor parte de los dilemas morales, derivados de la pandemia.

Finalmente, hay que reconocer que los valores del reino no son fáciles de conseguir. La verdad, como la gracia, a menudo cuesta cara Es responsabilidad de la comunidad de discípulos, de los tesligos del reino, asegurar, como lo hizo Jesucrislo, que el costo sea compartido, con la confianza de que, cuanlo más pesado sea el precio a pagar, mejor se saldará la cuenta.

\subsection{La presencia y el poder de Dios en la libertad}

La libertad de Dios en la creación y en la alianza ofrece la base de la libertad humana para escoger, así como expresa también la liberación gradual de la persona y de la sociedad - libertad y liberación que el reino de Dios busca, para lo cual capacita y alcanza, aunque en la historia sólo sea parcial. Según el programa mesiánico, anunciado por Lucas 4 , la base dę la liberación del reino ya está eslablecida. La esclavitud fundamental de la condición humana, personal y social, sagrada y profana, a causa del pecado y de la opresión, queda superada cuando los presos son liberados, los ciegos ven, los lisiados andan y a los pobres se les anuncia la buena nueva del reino. La libertad de los hijos de Dios es, a la vez, un don y un deber. Cuando una persona y una sociedad maduran, de manera que aprovechan sus propios recursos para su expresión creativa, se va configurando la forma humana de la liberación del reino.

Por lo que toca a la pandernia, el intento de liberarse de un contagio mayor, con medidas de prevención efectivas y humanas, es ya una respuesta fundamental a la llamada del reino. El desarrollo de medidas terapéuticas une la llamada del reino a la verdad y a la liberación de la esclavitud de la enfermedad. Aqui pudiera parece que chocan o pudieran chocar las diversas libertades. Programas de tests obligatorios - con el riesgo de cuarentena para personas con el VIH-SIDAson restricciones que recaen sobre personas que ya están oprimidas social o psicológicamente. En esta situación, la línea divisoria entre la libertad y la justicia debe ser trazada desde las libertades personales y los derechos sociales.

\subsection{La presencia y el poder de Dios en la justicia}

Para muchos estudiosos, la justicia es la descripción fundamental de Dios en Ja Escritura, en especial en las escrituras judías. Una comprensión más tradicional y simplista, pero menos analítica, tiende a poner en oposición al Dios de la 
justicia del Antiguo Testamento con el Dios del amor del Nuevo Testamento y la nueva alianza. En ambos casos, la justicia de Dios es la forma que adopta el amor de Dios, o, mejor dicho, el amor que es Dios, en alianza con el pueblo pecador de Israel y con la humanidad pecadora.

La justicia divina se caracteriza por el compromiso de Dios con y para el mundo y la humanidad, a través de las alianzas de la creación, con Abraham y Moisés, y en Jesucristo. Ese compromiso y responsabilidad requerían y permilían un compromiso y una responsabilidad por parte de la humanidad, y de los unos hacia los otros. Los grandes profetas de la justicia de Israel del siglo VIII a. C. denunciaron, como inaceplable a Dios, a quienes pretendía darle culto, pero despreciaban a las viudas, a los huérfanos y a los exiranjeros, así como a los jueces que se negaban a hacer justicia a los pobres (cfr. Amós). Para Jeremías, la fe en Dios se expresa fundamentalmente en la práctica de la justicia. En un lenguaje más fácil de entender en la actualidad, la verdadera verificación de la fe es el respeto y la respuesta hacia nuestros semejantes. La justicia y la igualdad que ella requiere se basan en la visión de los necesitados y marginados, que aparece tanto en el Nuevo como en el Anliguo Testamento. Los dichosos -hambrientos y sedientos de justicia- serán juzgados como discipulos de Dios por el modo en que dieron de comer a los hambrientos y cuidaron de los más necesitados. Dar de comer al hambriento es cuidar de Jesús, la encarnación de nuestro semejante más importarile.

Dicho de una manera más analítica, la justicia se divide en personal y social, como reguladora de la equidad, en las relaciones entre los individuos y en las relaciones esiruclurales con la sociedad. Muchos de los problemas derivados de la pandemia son problemas de justicia, personal y social. Algunos de ellos pertenecen al campo de los derechos humanos y desde ahí se puede luchar por ellos. Sin embargo, no todos los delicados problemas de la justicia se pueden traducir al lenguaje de derechos humanos, sin perder con ello un impacto ético considerable. Problemas como los análisis clínicos, por ejemplo, pueden ser considerados plenamente como pertenecientes al campo de los derechos humanos, pero en ocasiones esos análisis clínicos obligatorios son, a su vez, requisito importante para poder ser admitidos a seminarios y órdenes religiosas. En este caso, la libertad personal y la justicia siguen siendo derechos, mientras que estar abiertos a la verdad y mantener la paz en una comunidad pertenecen al ámbito del testimonio de vida. Los valores del reino se interrelacionan, en tensión.

\subsection{La presencia y el poder de Dios en la paz}

La paz es un tema muy abandonado en la teología, sobre todo en la teología moral, donde aparece, simplemente, como cuestión secundaria, en el debate sobre la guerra justa. Sin embargo, la paz es un problema fundamental en la tradición bíblica del reino, y cada vez es más importante para la supervivencia 
de la familia humana. En este caso, la presencia y el poder de Dios se manifiestan y se realizạ en la auténtica paz entre los individuos, entre y dentro de las sociedades. Hoy en 'día, representa el mayor desafío del reino para los discípulos de Jesucristo.

La paz, en la tradición bíblica, shalom en hebreo, supera ampliamente la minimalista ausencia de guerra, o la pax romana como mantenimiento de la ley y el orden. "Prosperar en comunión" puede ser una mejor descripción de la paz anunciada por el reino y que Jesús ofrece a sus discípulos, y, mediante ellos, al mundo. Se unen así las ideas de prosperidad en la unidad y en la solidaridad, lo cual implica respeto a la verdad, a la libertad y a la justicia. La paz también dice relación a temas cristianos más específicos como la armonia, la reconciliación y el perdón.

Según esto, la pandemia del VIH-SIDA fuerza a desarrollar una mejor comprensión y promoción de la paz como valor del reino. Realidades como la solidaridad, la armonía, la reconciliación y el perdón son claramente relevantes para responder a los desafíos, lanto personales como sociales, que supone el VIHSIDA. A su vez, la comprensión y aplicación de esos valores en este caso podrán ayudar a comprender y enfrentar mejor la necesidad de la paz y sus posibilidades, en otras situaciones.

\section{Los valores del reino y la sexualidad}

La presencia y el poder de Dios, que Jesús anunció como el reino, suponen una transformación personal, social y cósmica. A la hora de buscar una expresión moral del reino, hemos seleccionado cuatro valores estructurales, a los que hemos llamado primarios. Son fundamentales por sus raíces bíblicas, por su función estructural en la moral de vida $y$, sobre todo, por ser realidades del mismo Dios, según las tradiciones judía y cristiana. Esto no quiere decir que otros valores morales, que en comparación con los anteriores podrían ser descrilos como secundarios, no tengan también sus propias raíces biblicas, sus propias funciones en la moral de vida y no estén en relación, aunque sea indirecla, con Dios. Sin embargo, los valores primarios son los que iluminan estos valores secundarios, y pueden hacerlo en forma desconocida y fruclífera. Queremos ahora analizar algunos valores del reino, reales, pero secundarios, como la sexualidad y la caslidad, y ver cómo los valores primarios pueden influir en su comprensión y significado moral.

Comencemos diciendo que en la Biblia, Dios no es descrito o definido sexualmente, lo cual es notable en la historia de las religiones y es una característica específica de la religión judía. Esa tradición fundamental está caracterizada por la presencia creadora y el poder de Dios, desde los cuales fueron escritos los orígenes y el desarrollo de la sexualidad humana. En el comienzo del Génesis (Gn 1), Dios crea a la humanidad: "a imagen de Dios los creó; varón y 
hembra los creó". Dios dio el don de la dualidad sexual a los humanos, que, a su imagen y semejanza, fueron creados para el amor y la compañía, y para la procreación. Este tipo de amor humano, el amor sexual, es el que se celebra en el Cantar de los Cantares. Y en olros pasajes bíblicos se habla de él como espejo del amor de Dios hacia Israel (Josué, Isaías) y como sacramento o signo del amor de Cristo a la Iglesia, la comunidad de sus discípulos. En una visión teológica cristiana no hay cabida en absoluto para el síndrome de que "el sexo es cosa sucia".

El don divino de la sexualidad es, a la vez, un llamado y una responsabilidad para los seres humanos. Los objelivos que busca el amor - los objetivos humanos más elevados - se especifican muy bien en la sexualidad. Eslos objetivos deben buscarse a lo largo de un proceso, mediante el desarrollo y la integración del don sexual de una persona en el contexto de una vida de relaciones más amplia con las demás personas y la sociedad.

Las tradiciones católica y cristiana, apoyadas en este fundamento bíblico, consideran que el clímax del desarrollo de la sexualidad se realiza en el matrimonio. Según esta tradición, la plena expresión sexual de la persona se da en una comunidad establecida, aunque permanece siempre como comunidad en desarrollo, pues el amor de un hombre y una mujer es lo que hace que esa comunidad se abra siempre a uag nueva vida.

Si relacionamos ahora el valor "sexualidad" con lo que hemos llamado valores primarios del reino, podemos decir lo siguiente. La verdad, con sus acompanantes la fidelidad y la honestidad, pertenece y protege a esta comunidad matrimonial sacramental, tal como la describe la tradición católica. La libertad le es esencial y está en el origen del compromiso matrimonial, como aparece en la pregunta sobre la libertad que se hace al principio del rito matrimonial. La justicia pertenece en muchos sentidos al cumplimiento de la vocación al matrimonio. Visto desde su contrario, el adulterio es una forma de injusticia. Por último, el matrimonio no exisliría $\longrightarrow$ no sobreviviría- sin la paz y sus expresiones de comunión: la reconciliación y el perdón.

Según esto, la enseñanza moral católica sobre la sexualidad, aunque se centre fundamentalmente en el matrimonio, puede aprender mucho si se considera a éste desde los valores primarios analizados - lo cual puede facilitar también la difícil tarea de una educación adecuada a las generaciones futuras. Pues bien, esta consideración de la sexualidad — valor secundario del reino- puede iluminar también el enfoque moral de otras realidades que giran alrededor del SIDA.

Algo con to que tienen que luchar muchos enfermos del VIH-SIDA, sus compañeros y quienes los ayudan, es la homosexualidad. Esta lucha y este sufrimiento están causados, en parte, por los prejuicios y el rechazo social. Pero la vocación cristiana a la aceptación incondicional de todas las personas y en espe- 
cial de los marginados ha de aplicarse también, con toda claridad, a los homosexuales como personas. Esto no se consigue de un día para otro, sino que hay que educarse en el conocimiento de nuevas evidencias sobre los origenes y el desarrollo de la homosexualidad. Visto desde los valores primarios del reino, la verdad exige dicho proceso de educación, y la justicia y la libertad excluyen la discriminación de los homosexuales, así como la de cualquier otro "leproso". Por último, la paz, con lo que implica de unidad, reconciliación y perdón, confirma la necesidad de integrar la homosexualidad en una comunidad cristiana genuinamente inclusiva.

Desde los valores primarios del reino se pueden reexaminar también otras formas del ejercicio de la sexualidad. La comunidad cristiana y la Iglesia católica reconocen, por ejemplo, el don sexual y la llamada del reino a célibes, solteros y viudos, ellos y ellas. Más aún, el celibato ha jugado un papel significativo, a veces dominante, en la comprensión de la relación entre reino y sexualidad. La castidad "perfecta" del celibato era contrastada con la castidad "imperfecta" del matrimonio. Pero los célibes - y las personas no casadas — no son asexuales, ni son automática ni estadísticamente castos. La castidad no es algo con lo que nacen las personas y que se conserva, por decirlo de modo gráfico, con un poco de suerte. Ningún valor moral, ni ninguna virtud crecen de esa forma. Las personas llegan a ser caslas, como ya se ha dicho, a través de la integración de sus dones sexuales, en respuestas apropiadas a las diferentes relaciones que configuran sus vidas: marido-mujer, padre-hijo, hermano-hermana, amigos, vecinos, compañeros y conocidos. También los célibes y las personas no casadas son llamados a crecer, en el valor y la virtud de la castidad.

En este crecimiento, los valores fundamentales primarios del reino protegen y fomentan el valor de la castidad para los no casados, como lo hacen para los casados. Sin embargo, hay que admitir que en la tradición moral cristiana se ha pensado poco, en positivo, sobre cómo los no casados pueden crecer en la castidad. Los moralistas y los profesores se han contentado, normalmente, con simples pautas negativas: "no al acto sexual fuera del matrimonio". Pero reducir toda la vida sexual al acto sexual no es muy útil — tampoco para los casados. Los solteros, heterosexuales y homosexuales, necesitan una ayuda más útil, si es que quieren llegar a ser dinámicamente castos. Ellos también son llamados a ser personas, cuya sexualidad fomenta relaciones afeclivas y enriquecedoras, como signos y realizaciones de la presencia y del poder de Dios.

\section{El ministerio cristiano y la moralidad}

La reflexión bíblico filosófica que hemos hecho $-y$ teniendo en cuenta el contexto del ministerio que promueve Caritas Internationalis como respuesta a la pandemia - puede ser una ayuda importante para el debate sobre cuestiones morales prácticas, que surgen en el ministerio cristiano alrededor del SIDA. Lo 
fundamental del enfoque pastoral consiste en relacionar los problemas concretos de este ministerio con el ministerio personal de Jesús y con el ministerio de la comunidad de discípulos, que disciemen y promueven el reino, con énfasis en el servcio a los necesitados y marginados. Con este enfoque se conseguirá, al menos, que se haga evidente y se pueda superar de modo más fácil la distorsión moral que criticaba Jesús a quienes imponían cargas insoportables a los débiles.

Al estructurar estas breves reflexiones alrededor del VIH-SIDA vamos a considerar cualro puntos, en el conlexto del ministerio cristiano: acompañamiento, ayuda, casos típicos de la casuística y educación. Como aspectos del ministerio del reino, estas realidades pueden estar transidas de los valores del reino, tanto de los primarios, como de los secundarios.

\subsection{Acompañamiento}

El reconocimiento de los pobres y marginados que hace Jesús, hasta converlirse él mismo en su compañero de mesa, ofrece el modelo del ministerio cristiano con las personas con VIH-SIDA. La primera respuesta moral de los discípulos de Jesús tiene que ser la de acompañar a los enfermos y a los contagiados. Sin esta aceptación incondicional y sin la compañía duradera -más la atención profesional de los expertos-, el análisis moral teórico y la educación cristiana sobrel el VIH-SIDA carocen de autenticidad.

El acompañamiento (como modo de compartir el pan y la mesa), sin embargo, sólo será duradero a la larga, si se comparte el sufrimiento. Esta es una afirmación fundamental, que hay que analizar con cuidado. Es obvio que un ser humano no puede comprender del todo el sufrimiento de otro ser humano, $y$ nunca puede compartirlo de modo adecuado, ni siquiera al nivel del conocimien10. Y mucho menos puede una persona asumir o participar lísicamente del dolor de otra persona. Sin embargo, la comprensión y la compasión son algo más que el simple acompañamiento y ayuda. De hecho, el acompañamiento y la ayuda surgen y se mantienen al aceptar al olro y su sufrimiento en nuestro corazón, en nuestra mente y en nuestra imaginación.

Para comunicar estas experiencias, el lenguaje tiene límites obvios, pero quizás podamos decir que — a veces - otras personas pueden vivir en nosotros por su sufrimiento. Recibir compasivamente a los seres humanos más necesitados -aquellos que son "olros" para nosotros — es la clave del ministerio de Jesús. Dios acepla a Jesús, cuando Jesús vive el dolor, las privaciones y los defeclos (pecados) de todos los seres humanos. Esa es la clave de la doctrina de la salvación. Imitando a Jesús y a su Padre, sus discípulos se abren a los sufrimientos de los demás y, al mismo tiempo, respetan sus diferencias con ellos, como personas, incluso en el sufrimiento. 
Un acompañamiento "protector", que genera dependencia, no respeta a los que sufren, siendo así, además, que las personas que los cuidan tienen mucho que recibir de ellos. El acompañamiento está al servicio de la autoestima, la integridad y la autonomía de los demás. "Acompañamiento compasivo" -como lo hacian Jesús y Dios-, que implica crear con, sufrir con, redimir con y en la comunidad de ayuda, puede ser la mejor descripción de la primera obligación moral de los discípulos hacia las personas que viven con el VIH-SIDA.

\subsection{Ayuda}

Para que sea auléntico, el acompañamiento compasivo tiene que intentar ofrecer ayuda eficaz a los que sufren, darles ánimo y hacer que los enfermos puedan valerse por sí mismos, en la medida de lo posible. Aun teniendo en cuenta las limilaciones que ello impone a su libertad, la justicia tiene que expresarse en la ayuda. Sólo de esta manera se puede integrar la ayuda en la verdadera solidaridad y paz del reino. La ayuda - como la compasión y las otras dimensiones del ministerio- tienen que dejarse gujar siempre por estos valores primarios del reino.

La ayuda debe llevarse a cabo a todos los niveles, y no limitarse simplemente a la asistencia médica, aunque ésta sea esencial. Incluso en el ámbito médico, la vocación a la verdad, como búsqueda de un mejor conocimiento del origen, de la transmisión y de la manifestación del virus, tiene claras resonancias del reino. Otra exigencia del reino es la de asegurar que, sobre todo allá donde existen falsos mitos sobre el origen y la superación de la enfermedad, se difundan - afirmando la verdad- los conocimientos médicos. A veces, esos mitos se deben a la ignorancia. A veces se propagan debido a prejuicios sobre los llamados "desviados", como los homosexuales y drogadictos. De esa manera, se desconoce o se desvirtúa información importante sobre la transmisión heterosexual del virus.

La investigación sobre las causas del SIDA y la atención médica están todavía muy lejos de haber llegado a su meta, y hay que apoyarlas y consolidarlas lo más posible. Mientras tanto, hay que facilitar la mejor asistencia médica disponible, gratuita o de la manera más justa posible. Por lo demás, manipular a los que sufren con engaños o coerción, aunque sea apelando al tratamiento médico, viola la dignidad personal y los valores del reino. No es menos objetable la explotación económica por intereses médicos y farmacéuticos. En este sentido, la lucha por una distribución justa de las lerapias disponibles se ha convertido, de manera especial, en una responsabilidad cristiana, en un mundo donde los poderosos y los privilegiados monopolizan la medicina -así como otros recursos-, mientras que los necesitados, sobre todo los del tercer mundo, están expuestos a sufrir los peores estragos de la enfermedad. 
Los tratamientos médicos, incluso los que son más eficaces y están actualmente a nuestra disposición, no pueden conseguir por sí solos sanar la destrucción psicológica y social provocada por el VIH-SIDA. La asesoría, en este campo, sigue siendo crítica en la cura psicológica. La cura social, por su parte, implica medidas más radicales para superar prejuicios, promover el cambio cultural necesario y llevar a cabo la reforma económica. Por último, hay que estar claros en que algunos programas de ayuda, en especial aquellos que pueden suscitar problemas morales para los cristianos, serán eficaces - y eso será un elemento para juzgar sobre su moralidad- sólo a largo plazo. Esto se puede ilustrar con dos ejemplos.

Ayudar a los drogadictos, que ya viven con el VIH o están expuestos al contagio, necesita de cierto tiempo. La adicción a la droga no se cura de forma inmediata y con la mera voluntad. Para empezar, por lo general, es muy difícil lograr la actitud de disponibilidad a recibir ayuda. Durante ese período, más o menos largo, ayudar a que la gente se acostumbre a no intercambiar las agujas ya sería un paso importante, por pequeño que parezca, para salvar vidas y para acortar el tiempo de la recuperación.

En las situaciones de pobreza en que viven muchos drogadictos podría ser necesario - entre otras medidas - distribuir gratis agujas limpias, sin que esto significa aprobar de ningún modo la drogadicción, ni la cultura de la droga. Desde una perspectiva cristiana, que intenta evitar que los drogadictos se contagien unos a otros, y que las personas no infectadas sean infectadas por otras, se podría ver la distribución de agujas limpias como una medida provisional aceptable, cuando esa provisionalidad se usa para salvar vidas y ofrecer un poco de esperanza para afrontar y, finalmente, superar la adicción y la cultura de las drogas.

En otras siluaciones, como en la transmisión del VIH-SIDA, a través de relaciones sexuales con prostitutas y sus clientes - dentro del "turismo-sexual" y de la industria del sexo-, la conversión, como en el caso de los drogadictos, tampoco será inmediala. Esta "incapacidad" tiene raíces psicológicas, que varían según los individuos. Pero tiene también raíces sociales, culturales y económicas, incluso más poderosas, y varían de una sociedad y cultura a otra.

Según algunos estudios $-y$ tambien en la opinión pública-, para las prostitulas las razones económicas pueden ser las más poderosas. En estas situaciones, hay que analizar y enfrentar todas las dimensiones del problema para ayudar a personas con VIH/SIDA. Parte de esa ayuda consiste en prevenir que éstas lo propaguen todavía más. Todo esto lleva tiempo a las personas y a los colectivos. Durante ese tiempo, tomar en serio la vida puede implicar hacer uso de medidas provisionales, semejanles a la de proveer de agujas limpias para los drogadictos. Aun con el riesgo de incomprensión de que se está, aparentemente, apoyando el llamado "sexo seguro" y la promiscuidad, puede ser socialmente necesario y 
moralmente legítimo el uso de preservativos. No hay que considerarlo, en modo alguno, como un bien en sí mismo, pero es tolerable como una medida provisional para proteger la vida y ganar tiempo, en el proceso de conversión personal y social.

\subsection{La casuística}

El debate moral sobre la ayuda ya ha sacado a luz algunos casos lípicos de lo que en la Iradición se ha llamado "casuística". A pesar de que recientemente no goza de buena prensa entre los moralislas - y olros-, la casuística es un insirumento útil para precisar una respuesta cristiana a una serie de dificultades. Sin embargo, debe seguir jugando un papel subordinado y no debe dominar el discurso moral de la Iglesia, como a veces ha ocurrido, en el pasado.

Facilitar, aun con reticiencias, agujas limpias a los drogadictos que viven con o están amenazados por el VIH-SIDA es un problema muy real para la casuística. No se cuestiona el rechazo moral al uso de drogas. Lo que se cuestiona es cómo lograr que lo rechacen aquellos y aquellas que exponen sus propias vidas y ponen en peligro las de otros, compartiendo agujas. Liberar a estas personas de la esclavitud de las drogas supone salvarlos de la amenaza del VIHSIDA -y ello necesita tiempo. Las personas que están con aquellos cuya vida peligra - usando la casuística- son las que tienen que decidir, en casos particulares, hasta qué punto puede ayudar el facilitar agujas limpias.

Otras justificaciones para tomar este tipo de decisiones recurren al principio del mal menor: es moralmente justo intentar que alguien que va a hacer algo malo haga un mal menor. Herir es mejor que matar, si alguien va a disparar para matar a su vecino. En los debates sobre la guerra justa se pondera, desde una perspectiva moral, la proporción entre el mal del que se libera con la guerra y el mal que ésta traerá con seguridad. La teoría de la guerra justa reconoce lo inevilable que es el sufrimiento y el mal en una guerra, e intenta reducirlo en la medida de lo posible.

El principio del mal menor tiene sus limitaciones, pues ¿cómo se puede establecer lo que en realidad cuenta menos como mal? En teoría, ¿se puede considerar el mal, aunque sea menor, de alguna manera, como digno de aprobación? La distinción, adoptada hace poco por algunos moralistas, entre mal moral y pre-moral es muy controvertida por otros, en contextos como el de la contracepción y el aborto, que fue lo que dio lugar a dicha distinción. Finalmente, el principio del doble efecto ofrece las mismas dificultades que hemos analizado.

Una objeción más generalizada contra el principio del mal menor y sus variantes se basa en una visión estática de la realidad: en una determinada situación, por tiempo, aunque breve, se abandonan, aparentemente, los principios morales $-\mathrm{y}$ ello a costa de ventajas inciertas. Pero con una visión más dinámica 
se puede comprender mejor la finalidad de la praxis y los valores del reino: acompañar y ayudar a las personas más allá de su esclavitud actual. Visto desde esta perspectiva, se puede considerar como moralmente aceptable, y como primer paso hacia una transformación personal, cultural y comunitaria, sustituir agujas sucias por otras limpias. Esto es mucho más fácil de aceptar por quienes viven con los problemas prácticos que por quienes elaboran la teoría. Y bien puede ocurrir que una determinada teología moral apoye esta práclica, aunque no exista ninguna teoría satisfactoria del todo. En la vida y en el amor - las realidades cristianas y humanas más importantes-, la teoría con frecuencia cojea ante la práctica.

Este "ministerio de la casuística" puede ayudar a personas, cuyos comportamientos, en ciertas situaciones sexuales, conllevan el riesgo de contraer el VIHSIDA. Y nunca hay que olvidar que el crecimiento en los valores del reino debe comenzar allá donde está la persona. Lo que hay que hacer es apoyarla en lodo lo que sea moralmente posible para que pueda sobrevivir, en ese período de crecimiento.

Por lo que toca a los preservativos - problema que para algunos puede convertirse en obsesión一, hay que verlo en su contexto. Por una parte, cuando se exagera, de modo erróneo, la seguridad que ofrecen y se ignoran sus posibles fallos, humanos y mecánicos, se necesita, simplemente, honradez para decir la verdad. Por otra parte, si los preservativos son presentados para fomentar la promiscuidad o para explotar el mercado del sexo, hay que denunciarlo y oponerse a ello.

Este tipo de riesgos nunca se pueden excluir del todo, y hay que tenerlos muy en cuenta. Pero hay que mantener también la finalidad, en estas circunstancias, del uso de preservativos: liberar a las personas de poner en peligro sus vidas y darles la esperanza de un estilo de vida que sea humana y según el reino. En esta siluación, no parece que se aplique la prohibición de la Humanae Vitae del uso de anticonceptivos artificiales, porque interrumpen la conexión intrínseca entre la dimensión unitiva y procreativa del acto matrimonial. En el caso que ahora nos ocupa no existe la tal interrupción de un acto auténticamente unitivo. Cuando uno de los miembros del matrimonio es seropositivo, el efeclo del VIH crea tantas tensiones en la pareja que su relación más bien mueve a la compasión. La aceptación del uso del preservalivo sería para impedir que un acto de amor matrimonial, que, según las palabras de la Humanae Vitae, es vivificante, no se convierta en algo mortffero.

\subsection{La educación}

A anunciar y enseñar la buena nueva del reino, la comunidad de discípulos se compromete a educar a los demás. Para que esa educación sea efectiva, la comunidad tiene que poner en práctica lo que predica. Los discípulos también 
tienen que considerar el ministerio de la educación a partir del ministerio de Jesús. La conversión, la educación y la comunicación se basan, ante todo, en el testimonio. Por ello, una pastoral de acompañamiento, de ayuda y de la casuística, verdadera y compasiva, es el corazón del programa educativo de la Iglesia.

La educación es lambién un proceso en dos direcciones. Quienes quieren ser educadores tienen que ser ellos mismos educados. Los profesores tienen que escuchar y aprender. Ante el nuevo fenómeno del VIH-SIDA y su crecimiento continuo, sólo una Iglesia que aprende puede ser eficaz a la hora de enseñar. Indiquemos sólo un par de puntos, bastanle obvios, sobre el tema.

En la Iglesia, el aprendizaje de muchos de los aspectos de la pandemia y sus soluciones puede y tiene que ocurrir a muchos niveles. En este proceso de aprendizaje, las personas que viven con el VIH/SIDA, sus compañeros y quienes los asisten tienen mucho que aportar. Debido a su experiencia, pueden comprender muy bien algunas de las necesidades morales, pero también las posibilidades que se derivan de la pandemia. La interacción de la experiencia inmediata y la comprensión con la moral tradicional de la Iglesia puede conseguir resultados positivos. Sin embargo, esto requiere tiempo, y ningún análisis teológico ni teórico puede convergir adecuadamente con la experiencia práctica y la comprensión humana. Debe continuar, pues, la mutua educarión entre la Iglesia que experimenta y la Iglesia que enseña. Y todavia hay cuestiones pendientes muy serias.

Cambios pastorales, como los que hemos sugerido al hablar de la adición a las drogas y las relaciones sexuales, en el contexto del VIH-SIDA, no afectan todavía hoy seriamente las posiciones tradicionales de la Iglesia católica. La teología moral católica sufre de varias carencias, en el tema de la sexualidad. No tiene nada positivo que decir sobre la moral sexual fuera del matrimonio. $Y$ en un campo donde habría que tener en cuenta la experiencia para diferenciar y formular los problemas, se ha escuchado poco la experiencia de las mujeres. Por ello, la necesidad de subsanar estas carencias no proviene sólo de la crisis producida por la expansión del VIH-SIDA.

La enseñanza moral sobre la sexualidad, aunque se centre fundamentalmente en el matrimonio, tiene mucho que aprender de un significado más amplio de aquélla - y es además necesario, si se quiere facilitar una educación adecuada a las generaciones futuras. Uno de esos campos, en el que luchan muchos que viven con VIH-SIDA, sus compañeros y sus asistentes, es el de la homosexualjdad. Esta lucha y este sufrimiento están causados, en parte, por los prejuicios y el rechazo social. La llamada cristiana a la aceptación incondicional de todos y todas, y en especial de los marginados, ha de cumplirse claramente con los homosexuales como personas. No se puede conseguir de un día para otro. Se necesita educación, y ésta tendrá que estar abierta a nuevas evidencias sobre el 
origen y desarrollo de la homosexualidad. La verdad del reino de la paz, con lo que éste implica de unidad, reconciliación y perdón, confirma y refuerza la necesidad de integrar la homosexualidad en una genuina comunidad cristiana inclusiva.

No es todavía del lodo claro cuáles son los cambios —en actitudes y prácticas - que pueden producir nuevas evidencias sobre el origen de la homosexualidad y la reconsideración de las posiciones tradicionales. Pero parece razonable pensar que ésta ya no debe ser vista como autoindulgencia placenentera o capricho personal. Además, algunos hombres homosexuales han dado el testimonio de ayuda notable y amorosa a sus compañeros y amigos con VIH-SIDA. Esto debe ser muy apreciado, en su significado moral y cristiano. No se puede negar la superioridad moral de las relaciones estables entre hombres homosexuales sobre las relaciones casuales.

Esta educación, cuya necesidad se impone, a partir de la crisis del VIHSIDA, todavía no ha producido el debido impacto entre los responsables de la educación católica. No se puede predecir cuál puede ser el resultado de esta interacción. Mientras tanto, los compañeros, y quienes los ayudan, tienen que actuar con el mayor amor que les sea posible, usando las mejores ideas a su disposición.

La teología es siempre tarea inacabada. Continúan las historias, las atenciones y los sufrimientos, trágicos e inspiradores -y con ellas la reflexión teológica. Con lodos los sufrimientos y amenazas que tiene que afrontar la comunidad humana, las historias reales tienen que revelar también las nuevas posibilidades de redención y de liberación del inagotable reino de Dios. 